BMJ Paediatrics Open

\title{
Preterm infant outcomes in relation to the gestational age of onset and duration of prelabour rupture of membranes: a retrospective cohort study
}

Pramod Pharande, ${ }^{1,2}$ Mohamed E Abdel-Latif , ${ }^{3,4}$ Barbara Bajuk, ${ }^{5}$ Kei Lui, ${ }^{1,2}$ Srinivas Bolisetty, ${ }^{1,2}$ on behalf of the New South Wales and Australian Capital Territory Neonatal Intensive Care Units Audit Group

\section{ABSTRACT}

To cite: Pharande $P$, Abdel-Latif ME, Bajuk B, et al. Preterm infant outcomes in relation to the gestational age of onset and duration of prelabour rupture of membranes: a retrospective cohort study. BMJ Paediatrics Open 2017;1:e000216. doi:10.1136/ bmjpo-2017-000216

Received 10 October 2017 Revised 30 November 2017 Accepted 2 December 2017

\section{Check for updates}

${ }^{1}$ Division of Newborn Services, Royal Hospital for Women, Sydney, New South Wales, Australia

${ }^{2}$ School of Women's and Children's Health, University of New South Wales, Sydney, New South Wales, Australia ${ }^{3}$ Department of Neonatology, Centenary Hospital for Women and Children, Canberra, Australian Capital Territory, Australia

${ }^{4}$ Discipline of Neonatology, College of Medicine, Biology and Environment, Australian National University, Canberra, Australian Capital Territory, Australia ${ }^{5}$ Perinatal Services Network, Ministry of Health, New South Wales Pregnancy and Newborn Services Network (PSN), Randwick, New South Wales, Australia

Correspondence to Dr Pramod Pharande; Pramod. Pharande@monashhealth.org
Objective To determine the hospital outcomes of liveborn infants at 23-31 weeks following prelabour preterm rupture of membranes (PPROM).

Method A regional retrospective cohort study of 4454 infants of 23-31 weeks' gestation admitted to a tertiary neonatal network between 2007 and 2011. Primary outcome was the composite chronic lung disease (CLD) or mortality at discharge.

Results 225 (5\%) neonates had a history of PPROM occurring prior to $24^{+0}$ weeks (Early-PPROM), 829 (19\%) had a history of PPROM at or after $24^{+0}$ weeks' gestation (Late-PPROM) and 3400 (76\%) had no history of PPROM (No-PPROM). In comparison to No-PPROM, Early-PPROM group had higher CLD/mortality in infants born at 23-27 weeks (OR 1.95; 95\% $\mathrm{Cl} 1.34$ to 2.85) and 28-31 weeks (OR 4.98; $95 \% \mathrm{Cl} 2.99$ to 8.28). Within Early-PPROM group, the latency of PPROM >14 days had lower CLD/mortality in comparison to latency $\leq 14$ days $(57.6 \%$ vs $77 \%$, OR 0.40 ; $95 \% \mathrm{Cl} 0.21$ to 0.76 ). Late-PPROM group had significantly lower CLD/mortality in comparison to No-PPROM group at 23-27 weeks (OR 0.50; 95\% Cl 0.37 to 0.69 ) and 28-31 weeks (OR 0.50; $95 \% \mathrm{Cl} 0.36$ to 0.71 ). Within Late-PPROM group, latency $>14$ days was associated with an increased CLD/mortality in $28-31$ weeks ( $14.1 \%$ vs $5.4 \%$, OR 2.88 ; $95 \% \mathrm{Cl} 1.31$ to 6.38 ).

Conclusions Early-PPROM prior to 24 weeks' gestation had high incidence of CLD/mortality even after correcting for gestational age. Late-PPROM at or after 24 weeks had lower CLD/mortality compared with No-PPROM. Latency $>14$ days in Late-PPROM group at 28-31 week group increased the odds of CLD/mortality.

\section{BACKGROUND}

Prelabour preterm rupture of membranes (PPROM) refers to the rupture of amniotic membranes prior to 37 weeks' gestation and prior to the onset of labour. PPROM occurs in $2 \%-3 \%$ of pregnancies and accounts for $30 \%-40 \%$ of preterm births. ${ }^{1-3}$

PPROM has been reported to be associated with a fourfold increase in perinatal mortality and a threefold increase in neonatal morbidity,

\section{What is already known on this topic?}

Prelabour preterm rupture of membranes (PPROM) is an important cause of prematurity.

- It is unclear how age of onset of PPROM occurring before or after 24 weeks influences chronic lung disease (CLD) or mortality among preterm infants.

\section{What this study hopes to add?}

PPROM prior to 24 weeks results in significant CLD/ mortality.

- Late-PPROM at or after 24 weeks showed improved CLD/mortality compared with No-PPROM-related prematurity.

including respiratory distress syndrome, polymicrobial intra-amniotic infection and intraventricular haemorrhage (IVH). ${ }^{1} 45$ In particular, Early-PPROM occurring before $24^{+0}$ weeks' gestation has been reported to carry a high risk of chorioamnionitis and oligohydramnios in affected women with high mortality and morbidity in their neonates. ${ }^{6}$ In recent years, some institution-based studies reported improved hospital survival rates in preterm infants born following PPROM. ${ }^{7} 8$ However, there are no large population-based studies to suggest preterm infants born following PPROM have better or worse outcomes in comparison to those born following non-PPROM-related causes.

In this study, we included the latest cohort of extreme preterm infants admitted within a well-defined regional neonatal intensive care unit (NICU) network to test the hypothesis that extreme to very preterm infants born following PPROM have increased hospital mortality in comparison to non-PPROM-related aetiology. We also tested if Early-PPROM occurring before 
$24^{+0}$ weeks' gestation was associated with an increased rate of mortality and/or chronic lung disease (CLD) compared with those with no history of PPROM.

\section{METHODS}

This is a retrospective cohort study of infants born at $<32$ weeks' gestation and admitted to any of the NICUs in New South Wales and the Australian Capital Territory between January 2007 and December 2011. Data were obtained from the Neonatal Intensive Care Units' Data Collection, an ongoing prospective audit of infants admitted to any of the 10 NICUs in the region. Neonates with major congenital malformations or chromosomal anomalies were excluded.

Pulmonary hypoplasia was defined as a clinical sign of respiratory distress in the first days of life with confirmatory radiological appearance. Radiological presentation of pulmonary hypoplasia consisted of small lung fields with diaphragmatic domes elevated up to the seventh rib and bell-shaped chest. ${ }^{9}$ IVH was graded I-IV using criteria defined by Papile et al and retinopathy of prematurity (ROP) by the International Classification of Retinopathy of Prematurity. CLD was defined as the requirement for any respiratory support at 36 weeks' postmenstrual age. Other definitions and accuracy of the data have been documented previously. ${ }^{10}$

The primary outcome was the composite of death at hospital discharge and/or CLD.

For study purposes, women with PPROM prior to $24^{+0}$ weeks were defined as Early-PPROM, women with PPROM $\geq 24^{+0}$ weeks and $<32$ weeks' gestation were defined as Late-PPROM and women with no history of
PPROM (duration of rupture of membranes $<24$ hours) were defined as No-PPROM.

\section{Statistical analysis}

Statistical analyses were performed using SPSS (IBM; SPSS Statistics for Windows, V.22.0.0.0, Released 2013). Categorical outcome data are presented as percentages with OR and 95\% CI. Continuous data were tested for homogeneity of variance using Levene's test. Non-parametric variables were compared using either Mann-Whitney $\mathrm{U}$ test (for two-group comparison) or Kruskal-Wallis test (for multiple group comparison). Parametric variables were compared using either ' $t$ ' test (for two-group comparison) or analysis of variance (for multiple group comparison).

Multivariable logistic regression models were used to control for confounding factors and to elicit any independent influences. A two-tailed $\mathrm{P}$ value $<0.05$ was considered to be statistically significant.

\section{RESULTS}

Between 1 January 2007 and 31 December 2011, there were a total of 4501 preterm infants born at less than 32 weeks and admitted to participating NICUs. Forty-seven neonates were excluded and they comprised 44 neonates with major congenital anomalies, 2 neonates at 22 weeks and 1 neonate born at 24 weeks but admitted to NICU for palliative care. Of the remaining 4454 neonates included in the study, $225(5.1 \%)$ had a history of the onset of PPROM $<24^{+0}$ weeks' gestation (Early-PPROM), $829(18.6 \%)$ had a history of PPROM $\geq 24^{+0}$ weeks' gestation (Late-PPROM) and $3400(76.3 \%)$ had no history

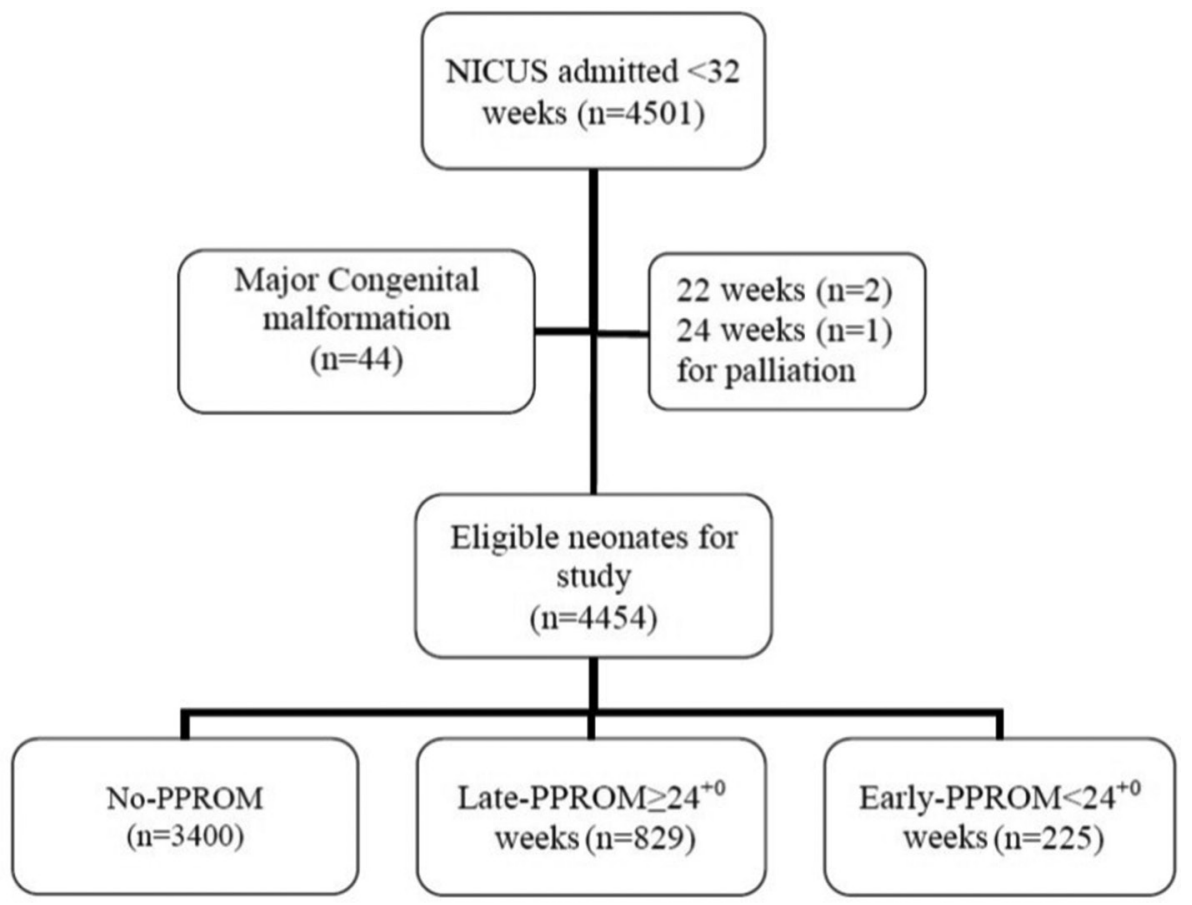

Figure 1 Flow chart of the study population. NICUS, Neonatal Intensive Care Units' Data Collection; PPROM, prelabour preterm rupture of membranes. 
Table 1 Maternal and neonatal characteristics among study groups

\begin{tabular}{|c|c|c|c|c|c|}
\hline & \multirow{2}{*}{$\begin{array}{l}\begin{array}{l}\text { No- } \\
\text { PPROM }(n=3400)\end{array} \\
n(\%)\end{array}$} & \multicolumn{2}{|c|}{ Late-PPROM $(n=829)$} & \multicolumn{2}{|c|}{ Early-PPROM $(n=225)$} \\
\hline & & n (\%) & $\begin{array}{l}\text { OR }(95 \% \mathrm{Cl}) / \text { mean } \\
\text { difference† }\end{array}$ & n (\%) & $\begin{array}{l}\text { OR }(95 \% \mathrm{Cl}) / \text { mean } \\
\text { difference† }\end{array}$ \\
\hline Caucasian ethnicity & $2655(78.1)$ & $658(79.4)$ & 1.08 (0.89 to 1.30$)$ & $186(82.7)$ & 1.33 (0.94 to 1.91$)$ \\
\hline Maternal age, years $\ddagger$ & $29.9(6.18)$ & $30.5(6.07)$ & $0.569^{\star}$ & $29.7(6.65)$ & -0.253 \\
\hline Multiple pregnancy & $1001(29.4)$ & $245(29.5)$ & 1.00 (0.85 to 1.18$)$ & $46(20.4)$ & 0.61 (0.44 to 0.85$)$ \\
\hline Chorioamnionitis§ & $480(14.1)$ & $341(41.1)$ & 4.25 (3.59 to 5.03 ) & $110(48.9)$ & 5.81 (4.40 to 7.68$)$ \\
\hline Maternal antibiotics & $1403(41.3)$ & $675(81.4)$ & 6.23 (5.17 to 7.52$)$ & $175(77.8)$ & 4.98 (3.61 to 6.87 ) \\
\hline $\begin{array}{l}\text { Antepartum } \\
\text { haemorrhage }\end{array}$ & $906(26.6)$ & $128(15.4)$ & $0.50(0.41$ to 0.61$)$ & 75 (33.3) & 1.37 (1.03 to 1.83 ) \\
\hline Preterm labour & $2143(63)$ & $661(79.7)$ & 2.30 (1.92 to 2.77$)$ & $172(76.4)$ & 1.90 (1.38 to 2.61$)$ \\
\hline $\begin{array}{l}\text { Hypertensive disease of } \\
\text { pregnancy }\end{array}$ & $807(23.7)$ & $33(4)$ & 0.13 (0.09 to 0.19$)$ & $9(4)$ & 0.13 (0.06 to 0.26$)$ \\
\hline Latency period $>14$ days & - & $70(8.4)$ & - & $151(67.1)$ & - \\
\hline Antenatal steroids & $2995(88)$ & $803(97)$ & 4.17 (2.78 to 6.25$)$ & $213(95)$ & 2.4 (1.33 to 4.33$)$ \\
\hline GA at PPROM & - & $28.14(26.2-29.5)$ & - & 22.14 (19.3-23) & - \\
\hline $\begin{array}{l}\text { Duration of PPROM } \\
\text { hours }\end{array}$ & - & $76(23-172)$ & - & 630 (205.5-1239) & - \\
\hline GA at birth, weeks $\ddagger$ & $28.6(2.15)$ & $29.09(1.82)$ & $0.49^{\star \star \star}$ & $26.4(2.28)$ & $-2.28^{\star \star \star}$ \\
\hline Male & $1794(52.8)$ & $423(51)$ & & $138(61)$ & 1.42 (1.07 to 1.87$)$ \\
\hline Birth weight, gł & 1246.9 (395.68) & $1367.4(334.05)$ & $120.4^{\star \star \star}$ & 965.8 (333.02) & $-281.09^{\star \star *}$ \\
\hline $\begin{array}{l}\text { Birth weight }<10 \text { th } \\
\text { percentile }\end{array}$ & $306(9)$ & $10(1.2)$ & 0.12 (0.06 to 0.23$)$ & $7(3.1)$ & 0.32 (0.15 to 0.69$)$ \\
\hline 5 min Apgar & $7.6(1.81)$ & $7.9(1.51)$ & $0.36^{\star \star \star}$ & $6.5(2.12)$ & $-1.04^{\star \star \star}$ \\
\hline Worst BD, first 12 hours $\ddagger$ & $-2.47(6.74)$ & $-2.31(5.12)$ & -0.15 & $-2.28(10.1)$ & -0.19 \\
\hline
\end{tabular}

Data presented as numbers $(\%)$, OR $(95 \% \mathrm{Cl})$ unless indicated otherwise.

${ }^{*} \mathrm{P}<0.05 ;{ }^{* *} \mathrm{P}<0.01 ;{ }^{* * *} \mathrm{P}<0.001$.

†In comparison to No-PPROM group.

$\ddagger$ Mean (SD).

$\S$ Clinical and/or histological chorioamnionitis.

IMedian (IQR).

$\mathrm{BD}$, base deficit; GA, gestational age; PPROM, prelabour preterm rupture of membranes.

of PPROM (No-PPROM) (figure 1). Data for the major primary outcomes were complete. Data on postnatal steroid usage and pulmonary hypertension were missing in $40(1.6 \%)$ and $46(1.9 \%)$ infants, respectively. Data on chorioamnionitis (clinical and or histopathological) were available for $75 \%$ of Early-PPROM group.

The maternal and neonatal demographics and characteristics are listed in table 1 . The mean maternal age was higher by 0.57 year in Late-PPROM group in comparison to No-PPROM group. The prevalence of chorioamnionitis was significantly higher in Early-PPROM and Late-PPROM groups compared with No-PPROM group (48.9\%, $41.1 \%$ and $14.1 \%$, respectively). In Late-PPROM group, chorioamnionitis was significantly higher in the group with latency of PPROM $>14$ days $(55.8 \%$ vs $39.8 \%$, $\mathrm{P}$ 0.013). The median duration of PPROM of 26.2 days (630 hours) was significantly longer in Early-PPROM group. The prevalence of antepartum haemorrhage (APH) was also significantly higher in Early-PPROM group $(33.3 \%)$. Antenatal steroid coverage was significantly higher in Early-PPROM (95\%) and Late-PPROM (97\%) groups compared with No-PPROM (88\%) group.

The mean gestational age (GA; 26 weeks) and birth weight $(966 \mathrm{~g})$ in the Early-PPROM group were significantly lower compared with other groups. No-PPROM group had a higher number of small for gestational age (SGA, birth weight $<10$ th percentile) neonates than in Late-PPROM and Early-PPROM groups, respectively (9\% vs $1.2 \%$ and $3.1 \%$ ).

Neonatal outcomes and interventions are described in table 2. The Early-PPROM group had a significantly higher prevalence of morbidities: air leaks, pulmonary hypertension, sepsis, patent ductus arteriosus (PDA), IVH $\geq$ grade III and ROP stage $\geq 3$. This group also had longer duration of respiratory support and hospitalisation and the need for high-frequency oscillation ventilation (HFOV), inhaled nitric oxide (iNO) therapy and home oxygen. However, Late-PPROM group had significantly less prevalence of air leaks, late-onset sepsis, CLD, home oxygen, severe IVH, necrotising enterocolitis, 
Table 2 Neonatal outcomes and interventions among study groups

\begin{tabular}{|c|c|c|c|c|c|}
\hline \multirow[b]{2}{*}{ Outcome } & \multirow{2}{*}{$\begin{array}{l}\text { No-PPROM }(\mathrm{n}=3400) \\
\mathrm{n}(\%)\end{array}$} & \multicolumn{2}{|l|}{ Late-PPROM $(\mathrm{n}=829)$} & \multicolumn{2}{|l|}{ Early-PPROM $(n=225)$} \\
\hline & & n (\%) & OR $(95 \% \mathrm{Cl}) \dagger$ & n (\%) & OR $(95 \% \mathrm{Cl}) \dagger$ \\
\hline Surfactant therapy & $2159(63.5)$ & $393(47.4)$ & 0.51 (0.44 to 0.60$)$ & $208(92.4)$ & 7.03 (4.26 to 11.59$)$ \\
\hline Air leak & $99(2.9)$ & $18(2.2)$ & 0.74 (0.44 to 0.60$)$ & $14(10)$ & 2.21 (1.24 to 3.93$)$ \\
\hline Pulmonary hypertension & $128(3.8)$ & $27(3.3)$ & 0.86 (0.56 to 1.31$)$ & 49 (21.8) & 7.11 (4.95 to 10.23$)$ \\
\hline Nitric oxide therapy & $106(3.1)$ & $22(2.7)$ & 0.84 (0.53 to 1.34$)$ & $47(20.9)$ & 8.20 (5.63 to 11.94$)$ \\
\hline HFOV & $346(10.2)$ & $40(4.8)$ & 0.44 (0.31 to 0.62$)$ & $94(41.8)$ & $6.33(4.75$ to 8.44$)$ \\
\hline $\begin{array}{l}\text { Conventional ventilation } \\
\text { supportł hours }\end{array}$ & $7.3(0-49.27)$ & $0(0-13.3)$ & - & $22.7(0.9-168)$ & - \\
\hline CPAP support $\neq$ hours & 145.95 (26.9-603.95) & $69.9(14.45-358.9)$ & - & $604.8(19.4-1076.45)$ & - \\
\hline Pulmonary hypoplasia & $3(0.1)$ & $1(0.1)$ & $1.36(0.14$ to 13.16$)$ & $11(4.9)$ & 58 (16.12 to 210.2$)$ \\
\hline Early-onset sepsis & $64(1.9)$ & $21(2.5)$ & 1.35 (0.82 to 2.23$)$ & $10(4.4)$ & $2.42(1.22$ to 4.78$)$ \\
\hline Late-onset sepsis & $627(18.4)$ & $119(14.4)$ & 0.74 (0.59 to 0.91$)$ & $72(32)$ & 2.08 (1.55 to 2.79$)$ \\
\hline Home oxygen & $173(5.4)$ & $23(3.1)$ & 0.53 (0.34 to 0.82$)$ & $41(18.2)$ & 4.15 (2.86 to 6.02$)$ \\
\hline ROP stage 2 or more & $146 / 2584(4.4)$ & $18 / 22(2.2)$ & 0.49 (0.30 to 0.81$)$ & 28/162 (12.4) & 3.49 (2.24 to 5.42$)$ \\
\hline IVH grade III/IV§ & $165 / 3254$ (4.9) & 20/784 (2.4) & 0.49 (0.30 to 0.78$)$ & 23/201 (10.3) & 2.41 (1.52 to 3.83$)$ \\
\hline NEC & $113(3.3)$ & $13(1.6)$ & 0.46 (0.25 to 0.82$)$ & $6(2.7)$ & \\
\hline PDA needing surgery & 109 (3.2) & $13(1.6)$ & 0.48 (0.26 to 0.85$)$ & $16(7.1)$ & 2.31 (1.34 to 3.97$)$ \\
\hline Postnatal steroid & 225 (6.6) & $20(2.4)$ & 0.34 (0.21 to 0.55$)$ & $45(20)$ & 3.52 (2.47 to 5.02$)$ \\
\hline Days in hospitalf & $40.5(20.5-67.7)$ & $35.7(17-56)$ & - & $65.4(16 .-99.6)$ & - \\
\hline CLD & $601(17.7)$ & $94(11.3)$ & 0.59 (0.47 to 0.75$)$ & $88(39)$ & 2.99 (2.25 to 3.96$)$ \\
\hline \multicolumn{6}{|l|}{ CLD among survivors } \\
\hline 23-27 weeks & $373 / 770(48.4)$ & $62 / 170(36.5)$ & 0.61 (0.43 to 0.86$)$ & $69 / 110(62.7)$ & 1.79 (1.18 to 2.71$)$ \\
\hline 28-31 weeks & $215 / 2364(9.1)$ & $32 / 636(5)$ & 0.52 (0.36 to 0.77 ) & $18 / 58(31)$ & 4.49 (2.53 to 7.98$)$ \\
\hline All GA weeks & $588 / 3134(18.8)$ & $94 / 806(11.7)$ & 0.57 (0.45 to 0.72$)$ & $87 / 168(51.8)$ & 4.65 (3.39 to 6.37$)$ \\
\hline \multicolumn{6}{|l|}{ Mortality } \\
\hline 23-27 weeks & $204 / 974(21)$ & $17 / 187(9)$ & 0.37 (0.22 to 0.63$)$ & 49/159 (31) & 1.68 (1.16 to 2.43$)$ \\
\hline 28-31 weeks & $62 / 2426(3)$ & $6 / 642(1)$ & 0.35 (0.15 to 0.83$)$ & $8 / 66(12)$ & 5.25 (2.40 to 11.48$)$ \\
\hline All GA weeks & $266 / 3400(7.8)$ & 23/829 (2.8) & 0.33 (0.21 to 0.51$)$ & $57 / 225(25.3)$ & 3.99 (2.88 to 5.53$)$ \\
\hline \multicolumn{6}{|l|}{ CLD/mortality } \\
\hline 23-27 weeks & $580 / 974(59.5)$ & $80 / 187(42.8)$ & 0.50 (0.37 to 0.69$)$ & 118/159 (74.2) & 1.95 (1.34 to 2.85$)$ \\
\hline 28-31 weeks & $280 / 2426(11.5)$ & $40 / 642(6.2)$ & 0.50 (0.36 to 0.71$)$ & 26/66 (39.4) & 4.98 (2.99 to 8.28$)$ \\
\hline All GA weeks & $860 / 3400(25.3)$ & $120 / 829(14.5)$ & 0.49 (0.40 to 0.61$)$ & $144 / 225(64)$ & 5.25 (3.95 to 6.96$)$ \\
\hline
\end{tabular}

Data presented as numbers $(\%)$, OR $(95 \% \mathrm{Cl})$ unless indicated otherwise.

†ln comparison to No-PPROM group.

$\ddagger$ Median (IQR).

§Denominator-number of examined babies.

CLD, chronic lung disease; CPAP, continuous positive airway pressure; GA, gestational age; HFOV, high-frequency oscillatory ventilation; IVH, intraventricular haemorrhage; NEC, necrotising enterocolitis; PDA, patent ductus arteriosus; PPROM, prelabour preterm rupture of membranes; ROP, retinopathy of prematurity.

PDA, severe ROP and less requirement for surfactant, and respiratory support including HFOV in comparison to No-PPROM group. Mortality was significantly less in Late-PPROM group in comparison to No-PPROM group, but the odds of mortality in Early-PPROM group was nearly four times of No-PPROM group.

Table 2 also shows the details of mortality, CLD among survivors and the composite CLD/mortality in three study groups stratified into two groups based on the GA at birth. Overall mortality rates in Early-PPROM, Late-PPROM and No-PPROM groups were 25.3\%,
$2.8 \%$ and $7.8 \%$, respectively. Overall CLD rates in three groups were $39 \%, 11.3 \%$ and $17.7 \%$, respectively. In comparison to No-PPROM group, mortality and CLD rates were significantly higher in Early-PPROM group at both $23-27$ weeks' gestation (31\% vs $21 \%$ for mortality and $62.7 \%$ vs $48.4 \%$ for CLD) and 28-31 weeks' gestation ( $12 \%$ vs $3 \%$ for mortality and $31 \%$ vs $9.1 \%$ for CLD). In contrast, Late-PPROM group had significantly less mortality, CLD and the composite outcome of CLD/ mortality in both gestational groups in comparison to No-PPROM group. 
Table 3 Chronic lung disease/mortality in relation to latency of PPROM

\begin{tabular}{|c|c|c|c|c|c|}
\hline \multirow{2}{*}{$\begin{array}{l}\text { GA at } \\
\text { birth, } \\
\text { weeks }\end{array}$} & \multirow[b]{2}{*}{$\begin{array}{l}\text { No-PPROM } \\
n=3400\end{array}$} & \multicolumn{2}{|l|}{$\begin{array}{l}\text { Late-PPROM } \\
\mathrm{n}=829\end{array}$} & \multicolumn{2}{|l|}{$\begin{array}{l}\text { Early-PPROM } \\
n=225\end{array}$} \\
\hline & & $\begin{array}{l}\leq 14 \text { days } \\
(n=759) \dagger\end{array}$ & $\begin{array}{l}>14 \text { days } \\
(n=70) \dagger\end{array}$ & $\begin{array}{l}\leq 14 \text { days } \\
(n=74) \dagger\end{array}$ & $\begin{array}{l}>14 \text { days } \\
(n=151) \dagger\end{array}$ \\
\hline All & $860 / 3400(25.3)$ & $\begin{array}{l}109 / 759(14.4) \\
0.49(0.39,0.62)^{\star \star \star}\end{array}$ & $\begin{array}{l}11 / 70(15.7) \\
0.55(0.28,1.05)\end{array}$ & $\begin{array}{l}57 / 74(77) \\
19.99(11.21,35.65)^{\star \star \star}\end{array}$ & $\begin{array}{l}87 / 151(57.6) \\
4.01(2.88,5.59)^{\star \star \star}\end{array}$ \\
\hline $23-27$ & $580 / 974(59.5)$ & $\begin{array}{l}78 / 181(43) \\
0.51(0.37,0.71)^{\star \star \star}\end{array}$ & $\begin{array}{l}2 / 6(33.3) \\
0.33(0.06,1.86)\end{array}$ & $\begin{array}{l}57 / 74(77) \\
4.42(2.39,8.2)^{\star \star \star}\end{array}$ & $\begin{array}{l}61 / 85(71.8) \\
1.72(1.05,2.81)^{\star}\end{array}$ \\
\hline $28-31$ & $280 / 2426(11.5)$ & $\begin{array}{l}31 / 578(5.4) \\
0.43(0.30,0.64)^{\star \star \star}\end{array}$ & $\begin{array}{l}9 / 64(14.1) \\
1.25(0.61,2.56)\end{array}$ & 0 & $\begin{array}{l}26 / 66(39.4) \\
4.98(2.99,8.28)^{\star * *}\end{array}$ \\
\hline
\end{tabular}

Data presented as numbers $(\%)$, OR $(95 \% \mathrm{Cl})$ unless indicated otherwise.

${ }^{*} \mathrm{P}<0.05 ;{ }^{* \star} \mathrm{P}<0.01 ;{ }^{* \star} \mathrm{P}<0.001$.

†In comparison to No-PPROM group.

GA, gestational age; PPROM, prelabour preterm rupture of membranes.

Table 3 shows the composite primary outcome in relation to the latency of PPROM. In comparison to No-PPROM group, the Early-PPROM group, irrespective of the latency, showed a significantly higher CLD/ mortality risk in both 23-27 and 28-31 weeks' GA categories; whereas Late-PPROM group had significantly lower CLD/mortality only in latency $\leq 14$ days group in both GA categories.

We conducted a within-group analysis in relation to latency of PPROM. Within Early-PPROM group, latency $>14$ days had significantly lower CLD/mortality in comparison to latency $\leq 14$ days $(57.6 \%$ vs $77 \%$, OR $0.40,95 \%$ CI 0.21 to 0.76 , P 0.004). Within Late-PPROM group, latency $>14$ days had a trend towards lower CLD/ mortality in 23-27 weeks' GA category (33\% vs $43 \%$, OR $0.66,95 \%$ CI 0.12 to 3.69 ) but significantly higher CLD/ mortality in $28-31$ weeks' GA category $(14.1 \%$ vs $5.4 \%$, OR $2.88,95 \%$ CI 1.31 to 6.38, P 0.015$)$. Within EarlyPPROM group, infants at 28-31 weeks' GA category had a significantly lower CLD/mortality in comparison to $23-27$ weeks' GA category (39.4\% vs $71.8 \%$, OR 0.26 , $95 \%$ CI 0.13 to $0.5, \mathrm{P}<0.001$ ). Within Late-PPROM group, 28-31 weeks' GA had significantly less CLD/mortality compared with $23-27$ weeks' GA $(6.2 \%$ vs $42.8 \%$, OR $0.08,95 \%$ CI 0.05 to $0.13, \mathrm{P}<0.001)$. These results are not shown in tables.

Multivariable logistic regression is shown in table 4 . Late-PPROM group and antenatal steroids were identified to be independently associated with reduced CLD/ mortality, whereas Early-PPROM group, latency >14 days, lower GA category (23-27 weeks), male gender and birth weight $<10$ th percentile were associated with higher CLD/mortality. Latency > 14 days in Early-PPROM and Late-PPROM groups increased the adjusted odds of CLD/mortality by twofold.

\section{DISCUSSION}

To our knowledge, this is the only multicentre study involving a large regional population to report on the most recent outcomes of liveborn infants born to women with a history of PPROM. PPROM is associated with manyfold increase in neonatal mortality and morbidity. However, it has not been previously shown whether PPROM would have more adverse outcomes in preterm infants compared with Non-PPROM-related causes of prematurity. Our study shows that PPROM had varied influence on CLD/mortality in preterm infants based on the onset and duration of PPROM. Early-PPROM occurring prior to 24 weeks was associated with a fivefold increase in CLD/mortality in comparison to No-PPROM group. In contrast, Late-PPROM occurring at or after 24 weeks' GA was associated with $50 \%$ less CLD/mortality in comparison to No-PPROM group.

\begin{tabular}{|c|c|c|}
\hline Variable & Adjusted OR $(95 \% \mathrm{Cl})$ & $P$ value \\
\hline $\begin{array}{l}\text { Late-PPROM versus No- } \\
\text { PPROM }\end{array}$ & 0.56 (0.43 to 0.72$)$ & $<0.001$ \\
\hline $\begin{array}{l}\text { Latency }>14 \text { days } \\
\text { vs } \leq 14 \text { days }\end{array}$ & 2.58 (1.54 to 4.31$)$ & $<0.001$ \\
\hline $\begin{array}{l}\text { Early-PPROM versus No- } \\
\text { PPROM }\end{array}$ & 1.98 (1.26 to 3.10$)$ & 0.003 \\
\hline $\begin{array}{l}\text { Latency }>14 \text { days } \\
\text { vs } \leq 14 \text { days }\end{array}$ & 1.92 (118 to 3.12$)$ & 0.008 \\
\hline $\begin{array}{l}\text { GA } 23-27 \text { weeks vs } 28- \\
31 \text { weeks }\end{array}$ & 9.45 (7.88 to 11.32$)$ & $<0.001$ \\
\hline Antenatal steroids & 0.69 (0.53 to 0.91$)$ & 0.007 \\
\hline Chorioamnionitis & 1.01 (0.82 to 1.26$)$ & 0.896 \\
\hline Multiple versus singleton & 0.92 (0.76 to 1.12$)$ & 0.420 \\
\hline $\begin{array}{l}\text { Male versus female } \\
\text { gender }\end{array}$ & 1.36 (1.14 to 1.61$)$ & $<0.001$ \\
\hline SGA versus AGA & 4.65 (3.52 to 6.15$)$ & $<0.001$ \\
\hline
\end{tabular}

AGA: $B W \geq 10$ th percentile. SGA: $B W<10$ th percentile. AGA, appropriate for gestational age; BW, birth weight; GA, gestational age; PPROM, prelabour preterm rupture of membranes; SGA, small for gestational age. 
Our study shows an interesting interaction between the latency and onset of PPROM. In Early-PPROM group, latency $>14$ days was associated with $60 \%$ reduction in CLD/mortality in comparison to shorter latency. The improved outcome within this group can be explained by higher gestation at birth. Our findings suggest that the longer the latency in Early-PPROM group, the better the outcome. Therefore, the practice of prolonging the pregnancy as long as possible in Early-PPROM group is justified. A few other small studies suggested a similar trend. Everest $e t a l^{7}$ in a single-centre retrospective study of 40 liveborn infants, reported $70 \%$ survival rate to discharge in a group of liveborn infants with a history of PPROM prior to 24 weeks' gestation plus a latent period of at least 14 days before delivery. Williams et $a l^{11}$ reported a retrospective case analysis of 23 pregnancies complicated by PPROM prior to 25 weeks' gestation. They reported survival of $78 \%$ in 15 infants who were born after 24 weeks with a latency of $>14$ days; seven of these infants (78\%) responded to HFOV and iNO therapy with good clinical response. Soylu $e t \mathrm{al}^{12}$ reported a $76 \%$ survival to discharge in a group of preterm infants born at $<32$ weeks following PPROM at $<24$ weeks' gestation and a latency of $>7$ days. Shah and Kluckow ${ }^{8}$ reported a $90 \%$ survival to discharge in preterm infants born after PPROM at 24 weeks or less with a latent period of 14 days though the cohort consisted of more mature infants (mean GA $27.8 \pm 5.3$ weeks and birth weight $1207 \pm 783 \mathrm{~g}$ ) when compared with our cohort.

In contrast, Late-PPROM group showed a different interaction based on the GA at birth. The better outcomes (decreased CLD/mortality) in Late-PPROM group can be explained by various factors as Late-PPROM group had higher antenatal steroid coverage $(97 \%$ vs $88 \%)$, was more mature (higher mean GA (29.1 weeks vs 28.6 weeks) and birth weight (1367 g vs $1247 \mathrm{~g})$ ) and had significantly less number of SGA infants $(1.2 \%$ vs $9 \%)$ as compared with No-PPROM group. Latency $>14$ days had no significant influence on CLD/mortality in Late-PPROM infants born at 23-27 weeks. However Late-PPROM group born at 28-31 weeks following latency $>14$ days was associated with a threefold rise in CLD/mortality $(14.1 \%$ vs $5.4 \%$, OR $2.88,95 \%$ CI 1.31 to 6.38 , P 0.015 ). A recently published study by Lorthe $e a^{13}$ from national population-based EPIPAGE2 cohort of preterm neonates delivered after PPROM at 24-32 weeks' gestation concludes that for a given GA at birth, prolonged latency duration after PPROM does not worsen neonatal prognosis. A crude association found between prolonged latency duration and improved survival disappeared on adjusting for GA at birth. This contradicts our study findings. The worse neonatal outcomes in Late-PPROM group after latency $>14$ days may be explained by higher chorioamnionitis $(55.8 \%$ vs $39.8 \%, \mathrm{P} 0.013)$ in that group.

There were a number of perinatal complications noted in our PPROM groups. APH and chorioamnionitis are known complications in pregnancy following PPROM. The prevalence of APH of $33.3 \%$ in our Early-PPROM group is within the range reported by other studies. Manuck et $a l^{14}$ reported an overall placental abruption incidence of $75 \%$ in a cohort of 159 women who experienced PPROM before 24 weeks' gestation and Deutsch et $a l^{15}$ reported $25 \%$ APH in a cohort of 105 women who had mid-trimester PPROM before 24 weeks.

Over $40 \%$ of women in the Early-PPROM and LatePPROM groups in our study had clinical and/or histologically proven chorioamnionitis. This was probably an underestimate as data on chorioamnionitis were incomplete. This was despite over $78 \%$ of women in both PPROM groups receiving antibiotics prior to labour. There were similar findings in other studies. Everest $e t a l^{7}$ reported histological chorioamnionitis in $60 \%$ of women. Soylu et $a l^{12}$ found $30 \%$ of women with clinical chorioamnionitis and Manuck et $a l^{14}$ reported 54\%. Gomez et al ${ }^{16}$ demonstrated that intra-amniotic inflammation can develop despite antibiotic therapy for women with PPROM.

Both respiratory and non-respiratory neonatal morbidities were high in the Early-PPROM group. Nearly $40 \%$ of the group developed CLD and $18 \%$ were discharged home on oxygen. Many other recent studies also reported a high incidence of CLD ranging from $34 \%$ to $55 \% .^{781112}$ Other respiratory morbidities were also significantly higher in our Early-PPROM group including air leak $(10 \%)$, postnatal steroids $(20 \%)$, pulmonary hypertension $(21.8 \%)$, iNO therapy $(20.9 \%)$ and prolonged duration of respiratory support. Non-respiratory morbidities were also significantly higher including severe IVH $(10.3 \%)$, lateonset sepsis (32\%) and severe ROP (12.4\%).

Many of these morbidities can be explained by the earlier GA of Early-PPROM group, but these morbidities were significantly higher in the Early-PPROM group even after correcting for GA. The mechanism underlying these high morbidities and mortalities in this group can be explained by a combination of altered antenatal lung development, infection and the fetal inflammatory response syndrome (FIRS) induced by PPROM and associated chorioamnionitis. ${ }^{17}$ Hecht et $a l^{18}$ demonstrated a strong inflammatory signal in the blood of preterm infants born before 28 weeks' gestation whose placentas showed histological chorioamnionitis. At these early weeks of gestation, spontaneous preterm deliveries without PPROM are known to be associated with intrauterine infection/inflammatory response. FIRS is associated with high rates of long-term morbidities such as cerebral palsy and developmental delay. ${ }^{19-22}$ But a recent report by PIPARI study collaborators ${ }^{23}$ suggests that clinical chorioamnionitis does not have a major independent role in the pathogenesis of neurodevelopmental problems in very preterm infants. The authors ${ }^{24}$ argue that rather than chorioamnionitis other underlying pathologies behind preterm delivery may be contributory to preterm brain injury.

A recent report from the EPIPAGE2 collaborators ${ }^{25}$ contrasts our findings and suggests that among neonates born between 24 and 34 weeks' gestation, in-hospital mortality due to PPROM was not statistically significant. 
But neonates with fetal growth restriction had higher mortality risk (adjusted OR 3.0, 95\% CI 1.9 to 4.7 ) than those born after preterm labour. There are also those $\mathrm{e}^{26} 27$ who propose that SGA and preterm birth comprise a double-hit injury highly predisposing to increased mortality and CLD. In our study, SGA was an independent risk factor for increased mortality/CLD.

With improving survival, we need to focus on reducing the serious morbidities in these infants and our current obstetric and neonatal practices need to be reviewed in achieving these goals. We do not have the data on type and duration of maternal antibiotics used. Maternal antibiotic therapy has shown to prolong the latency of pregnancy, reduce FIRS and thereby reduce the morbidities, ${ }^{28}$ but it remains unclear which antibiotic regime is better to achieve these results. ${ }^{29}$ The focus may still need to be on the antenatal interventions to reduce the fetal inflammatory response.

We acknowledge the limitations of the study. The cohort is confined to NICU admissions and did not report on stillbirths, terminations of pregnancy and neonatal deaths prior to NICU admission. Long-term outcome data are also not available for this cohort. However, the main strengths are a large cohort from a well-defined geographic region and prospectively collected comprehensive data outcomes.

In conclusion, neonates with a history of PPROM prior to 24 weeks' gestation have worse outcomes when compared with Late-PPROM or No-PPROM. Clinicians should focus on interventions to prolong the latency and reduce the fetal inflammatory response.

Acknowledgements The authors thank the directors, the NICUS members and the audit officers of all tertiary units in supporting this collaborative study: NICUS, Dr Jennifer Bowen (chairperson), Barbara Bajuk (coordinator), Sara Sedgley (research officer); Canberra Hospital, Dr Hazel Carlisle (director), Judith Smith; John Hunter Children's Hospital, Dr Paul Craven (director), Lynne Cruden, Alissa Argomand; Royal Prince Alfred Hospital, Ingrid Rieger (director), Dr Girvan Malcolm, Tracey Lutz (clinical director), Shelley Reid; Liverpool Hospital, Dr Jacqueline Stack (director), Dr lan Callander, Kathryn Medlin, Kaye Marcin; Nepean Hospital, Dr Vijay Shingde, Mee Fong Chin, Kerrie Bonzer; The Children's Hospital at Westmead, Professor Nadia Badawi (director), Dr Robert Halliday, Caroline Karskens; Royal North Shore Hospital, Dr Mary Paradisis (director), Associate Professor Martin Kluckow, Claire Jacobs; Sydney Children's Hospital, Dr Andrew Numa (director), Dr Gary Williams, Janelle Young; Westmead Hospital, Dr Melissa Luig (director), Jane Baird; and Royal Hospital for Women, Associate Professor Kei Lui (director), Dr Julee Oei, Diane Cameron. We also thank the babies and their families, the nursing and midwifery, obstetric and medical records staff of the obstetric and children's hospitals in NSW and the ACT.

Contributors PP conceptualised and designed the study, analysed and interpreted the data, and drafted the initial manuscript. ALM and KL contributed to the initial concept and design of the study, analysis and interpretation of data. BB designed the data collection instruments, coordinated and supervised data collection, and critically reviewed the manuscript. SB conceptualised and designed the study, coordinated and supervised data analyses and manuscript write-up, and reviewed and revised the manuscript. All authors approved the final manuscript as submitted and agreed to be accountable for all aspects of the work.

Competing interests None declared.

Ethics approval South Eastern Sydney and Illawarra Area Health Service Human Research Ethics Committee-Northern Sector

Provenance and peer review Not commissioned; externally peer reviewed.
Open Access This is an Open Access article distributed in accordance with the Creative Commons Attribution Non Commercial (CC BY-NC 4.0) license, which permits others to distribute, remix, adapt, build upon this work non-commercially, and license their derivative works on different terms, provided the original work is properly cited and the use is non-commercial. See: http://creativecommons.org/ licenses/by-nc/4.0/

(c) Article author(s) (or their employer(s) unless otherwise stated in the text of the article) 2017. All rights reserved. No commercial use is permitted unless otherwise expressly granted.

\section{REFERENCES}

1. ACOG Committee on Practice Bulletins-Obstetrics. ACOG practice bulletin no. 80: premature rupture of membranes. clinica management guidelines for obstetrician-gynecologists. Obstet Gynecol 2007;109:1007-19.

2. Mercer BM. Preterm premature rupture of the membranes: diagnosis and management. Clin Perinatol 2004;31:765-82.

3. Mercer B, Milluzzi C, Collin M. Periviable birth at 20 to 26 weeks of gestation: proximate causes, previous obstetric history and recurrence risk. Am J Obstet Gynecol 2005;193(Pt 2):1175-80.

4. Dale PO, Tanbo T, Bendvold E, et al. Duration of the latency period in preterm premature rupture of the membranes. Maternal and neonatal consequences of expectant management. Eur J Obstet Gynecol Reprod Biol 1989;30:257-62.

5. Bengtson JM, VanMarter LJ, Barss VA, et al. Pregnancy outcome after premature rupture of the membranes at or before 26 weeks' gestation. Obstet Gynecol 1989;73:921-7.

6. Yeast JD. Preterm premature rupture of the membranes before viability. Clin Perinatol 2001;28:849-60.

7. Everest NJ, Jacobs SE, Davis PG, et al. Outcomes following prolonged preterm premature rupture of the membranes. Arch Dis Child Fetal Neonatal Ed 2008;93:F207-11.

8. Shah DM, Kluckow M. Early functional echocardiogram and inhaled nitric oxide: usefulness in managing neonates born following extreme preterm premature rupture of membranes (PPROM). J Paediatr Child Health 2011;47:340-5.

9. Leonidas JC, Bhan I, Beatty EC. Radiographic chest contour and pulmonary air leaks in oligohydramnios-related pulmonary hypoplasia (Potter's syndrome). Invest Radiol 1982;17:6-17.

10. Bajuk B. Validation of the neonatal intensive care units' data collection. Proceedings of the 5th Annual Conference of the Perinatal Society of Australia and New Zealand; 13-16 March 2001, Canberra. Canberra, Australia: Perinatal Society of Australia \& New Zealand, 2001.

11. Williams $\mathrm{O}$, Hutchings $\mathrm{G}$, Debieve $\mathrm{F}$, et al. Contemporary neonatal outcome following rupture of membranes prior to 25 weeks with prolonged oligohydramnios. Early Hum Dev 2009;85:273-7.

12. Soylu H, Jefferies A, Diambomba Y, et al. Rupture of membranes before the age of viability and birth after the age of viability: comparison of outcomes in a matched cohort study. J Perinatol 2010;30:645-9.

13. Lorthe $\mathrm{E}$, Ancel $\mathrm{PY}$, Torchin $\mathrm{H}$, et al. Impact of latency duration on the prognosis of preterm infants after preterm premature rupture of membranes at 24 to 32 weeks' gestation: a national populationbased cohort study. J Pediatr 2017;182:47-52.

14. Manuck TA, Eller AG, Esplin MS, et al. Outcomes of expectantly managed preterm premature rupture of membranes occurring before 24 weeks of gestation. Obstet Gynecol 2009;114:29-37.

15. Deutsch A, Deutsch E, Totten C, et al. Maternal and neonatal outcomes based on the gestational age of midtrimester preterm premature rupture of membranes. J Matern Fetal Neonatal Med 2010;23:1429-34.

16. Gomez R, Romero R, Nien JK, et al. Antibiotic administration to patients with preterm premature rupture of membranes does not eradicate intra-amniotic infection. J Matern Fetal Neonatal Med 2007;20:167-73.

17. Williams $\mathrm{O}$, Hutchings $\mathrm{G}$, Hubinont $\mathrm{C}$, et al. Pulmonary effects of prolonged oligohydramnios following mid-trimester rupture of the membranes-antenatal and postnatal management. Neonatology 2012;101:83-90.

18. Hecht JL, Fichorova RN, Tang VF, et al. Relationship between neonatal blood protein concentrations and placenta histologic characteristics in extremely low GA newborns. Pediatr Res 2011;69:68-73.

19. Gotsch F, Romero R, Kusanovic JP, et al. The fetal inflammatory response syndrome. Clin Obstet Gynecol 2007;50:652-83.

20. Gomez R, Romero R, Ghezzi F, et al. The fetal inflammatory response syndrome. Am J Obstet Gynecol 1998;179:194-202. 
21. Shim SS, Romero R, Hong JS, et al. Clinical significance of intraamniotic inflammation in patients with preterm premature rupture of membranes. Am J Obstet Gynecol 2004;191:1339-45.

22. Yoon BH, Romero R, Park JS, et al. Fetal exposure to an intraamniotic inflammation and the development of cerebral palsy at the age of three years. Am J Obstet Gynecol 2000;182:675-81.

23. Ylijoki M, Lehtonen L, Lind A, et al. Chorioamnionitis and five-year neurodevelopmental outcome in preterm infants. Neonatology 2016;110:286-95

24. Ylijoki M, Ekholm E, Haataja L, et al. Is chorioamnionitis harmful for the brain of preterm infants? A clinical overview. Acta Obstet Gynecol Scand 2012;91:403-19.
25. Delorme P, Goffinet F, Ancel PY, et al. Cause of preterm birth as a prognostic factor for mortality. Obstet Gynecol 2016;127:40-8.

26. Zeitlin J, El Ayoubi M, Jarreau PH, et al. Impact of fetal growth restriction on mortality and morbidity in a very preterm birth cohort $J$ Pediatr 2010:157:733-9.

27. O'Shea JE, Davis PG, Doyle LW. Maternal preeclampsia and risk of bronchopulmonary dysplasia in preterm infants. Pediatr Res 2012;71:210-4

28. Mercer BM, et al. Antibiotic therapy for reduction of infant morbidity after preterm premature rupture of the membranes. JAMA 1997;278:989-95.

29. Kenyon S, Boulvain M, Neilson JP. Antibiotics for preterm rupture of membranes. Cochrane Database Syst Rev 2013;12:CD001058. 